\title{
Movement Ecology of Potamodromous Top Predator in a Large Lake: Synchrony and Coexistence of Distinct Migratory Patterns
}

Silviya V. Ivanova ( $\square$ sivanova2018@gmail.com )

Great Lakes Institute for Environmental Research, University of Windsor, 401 Sunset Ave, Windsor, Ontario N9B 3P4, Canada https://orcid.org/0000-0003-2886-8533

Timothy B Johnson

Ontario Ministry of Natural Resources and Forestry

Aaron T Fisk

University of Windsor

\section{Research}

Keywords: migrations, potamodromy, movement corridors, acoustic telemetry, great lakes, lake trout, management strategies, species rehabilitation

Posted Date: August 26th, 2020

DOI: https://doi.org/10.21203/rs.3.rs-63972/v1

License: (c) (1) This work is licensed under a Creative Commons Attribution 4.0 International License. Read Full License

Version of Record: A version of this preprint was published at Transactions of the American Fisheries Society on July 20th, 2021. See the published version at https://doi.org/10.1002/tafs.10325. 


\section{Abstract}

Migrations are a key component of the life-histories of many highly mobile animals. The study of potamodromous migrations occurring within large lakes have lagged and are poorly understood for most species. This is an issue for restoration efforts and adaptive management, as understanding the movement of species, and underlying patterns and mechanisms are essential for identifying key habitat and quantifying the species role in the ecosystem. Using acoustic telemetry, this study quantified the spatio-temporal movements and migratory patterns of lake trout (Salvelinus namaycush), an iteroparous, potamodromous predator in Lake Ontario, the $13^{\text {th }}$ largest lake by volume in the world that is highly managed and supports a diverse fish community of native and non-native species. Over 2.5 years (December 2016 to April 2019), the movements of 41 lake trout were quantified across a large array of 196 acoustic receivers in Lake Ontario. Individual analysis revealed annual convergence in the fall at a location other than the spawning grounds, followed by synchronized migrations to spawning sites. Consistent with divergent migrations, out-migration was asynchronous, stretching over a longer period of time than pre-spawning movements and across multiple routes. At least two groups of individuals with distinct migratory behaviors, i.e. contingents, were identified in the population. These results illustrate the presence of contingents and provide key information on migratory patterns, convergence points and routes in a potamodromous top predator population in a large lake. Thus, we provide evidence that contingents with different behavior used different habitats across seasons. As such, this study informs management on the potential success and implications of employing different rehabilitation strategies, such as diversifying a species' population through selective strain stocking in large deep lakes to aid reestablishment across habitats. This knowledge would improve modelling of community dynamics, understanding of nutrient cycling, and overall ecosystem function of large lakes.

\section{Introduction}

Animals migrate between habitats to meet needs associated with their life-history traits and often repeatability and predictability differentiate migrations from other movements (Ben B. Chapman et al., 2014; Dingle, 2014). Habitat heterogeneity is a major driver of migration, with habitats or regions offering conditions that enhance reproduction and offspring survival. For example, thick-billed murres (Uria lomvia) migrate to areas with plentiful high quality prey crucial to lay eggs and raise young (Robinson \& Minton, 1989). Other migrations are to areas where physico-chemical conditions (e.g. temperature or oxygen), are most favorable for fish egg and fry development, such as for lake sturgeon (Acipenser fulvescens) (Bemis \& Kynard, 1997). Migratory movements can cover short or long distances (T.R. Binder et al., 2011), varying even within populations of the same species, for example, European eel (Anguilla anguilla) populations can migrate $>1,000 \mathrm{~km}$ (Righton et al., 2016), and others $<100 \mathrm{~km}$ (Arai, 2014). Migrations are an integral part of the life histories of many species and quantifying them and the underlying mechanisms are important steps to understanding a species' ecology, and necessary for effective management and conservation. 
The underlying processes of migration differ between marine and freshwater environments, species, and often strains or life stages of the same species, resulting in different timing, duration, and distance travelled (Quinn, 2005). By definition, migration is a coordinated movement of a species or population between different habitats (Dingle, 2014). Distinct migratory strategies and/or behaviors can co-occur within or among populations (Secor, 1999) as a result of the existence of 'contingents', defined here as subgroups of individuals within a population that differ in their use of habitat and/or migratory behavior. For some species, migration is time-synchronized between individuals in both directions (Ben B. Chapman et al., 2014). For others, it is only synchronized one way and return migration is considered dispersal because it may not occur in a similarly organized pattern (Ben B. Chapman et al., 2014; Russell, 1937).

Convergence is a phenomenon observed prior to the migration of many species and may also occur between different genetic strains or populations. Pacific salmon stocks from coastal and offshore waters of the northern Pacific Ocean converge at the mouth of the Fraser River for staging prior to movement upriver (Quinn, 2005). Possible benefits of convergence prior to spawning migration include mixing of strains to ultimately facilitate genetic exchange. Other species, such as white sharks (Carcharodon carcharias), do not converge prior to migrations but instead aggregate at mating sites (Domeier \& NasbyLucas, 2013). Convergence as a component of migrations is a key clue to a species' ecology and adds valuable knowledge with practical applications. Potamodromous migrations (these occurring only within freshwater environments, such as lakes and rivers), often characterized by shorter distance and duration, have been scarcely studied, the underlying processes poorly understood and records of convergence are difficult to find (Thurow, 2016).

Potamodromous migrations occurring only within large lakes without migration to rivers have been particularly difficult to study due to the volume/surface area of the waterbody and the requirement for long-term continuous monitoring. As such, the occurrence, nature and mechanisms of such migrations are still largely unknown for many species. Large lakes offer habitat heterogeneity not present in smaller lakes, and populations living in the latter may not exhibit the same movement and migratory behaviors or variation as these in larger waterbodies (Klinard et al., 2018). Thus, fish populations in small lakes are not useful as models for understanding movements and migrations in large lakes. Further, complete seasonal and multi-year continuous datasets are crucial for understanding migrations, but until recently were difficult to compile. The development in passive acoustic telemetry tracking technologies has removed this barrier and here, we take advantage of the growing use of acoustic telemetry in the Laurentian Great Lakes to examine the movement ecology of a potamodromous top predator and understand if migratory patterns exist and their mechanisms in a large deep lake.

Quantifying the timing of movements, consistency and the influence of bathymetry in lakes for potamodromous species would improve stock assessment and management of fisheries. Indeed, identifying spawning migrations have guided stocking locations of hatchery raised fish (Martin J. Hansen \& Stauffer, 1971). This information would help identify spatial and social dynamics between wild and hatchery origin conspecifics, to understanding uncertainties and bias in population estimates (Adkison \& 
Cunningham, 2015), and to prepare for current and growing climate change impacts on large freshwater ecosystems (Wuebbles et al., 2019), including in the Laurentian Great Lakes (hereafter Great Lakes; Haynes and Keleher, 1986). Given animals movements and migration influence the cycling of nutrients (Vannini et al., 2012), the new knowledge would also provide greater understanding of the function of the ecosystem. Thus, studying the movement ecology and migratory behavior of species is not only crucial to understanding the life-history needs of an animal of interest, but contributes information that is key to species and ecosystem management.

Lake trout are a long-lived iteroparous species that generally inhabit cold waters (Stewart, Weininger, Rottiers, \& Edsall, 1983), known to exhibit resident, potamodromy or anadromy migratory strategies with the coexistence of contingents (Thomas R Binder et al., 2017; Harris et al., 2014; Muhlfeld et al., 2012; Riley et al., 2018). Movements to shallower depths ( $<10 \mathrm{~m}$ ) have been documented towards spawning grounds in Lake Ontario and Superior (Fitzsimons, 1995a; Micheal J. Hansen, 1999). The species' general movements in large lakes are known mainly from surveys and mark-recapture studies (Landsman et al., 2011). Complete continuous data across all seasons and multiple years are rare, and studies documenting lake trout migratory behavior are relatively scarce (Thomas R Binder et al., 2017; Riley et al., 2018) and lacking for Lake Ontario.

Lake trout is a native apex predator in the Great Lakes that declined substantially in the mid-1900s (Christie, 1972; Fitzsimons, Brown, Honeyfield, \& Hnath, 1999; Schneider, Kolenosky, \& Goldthwaite, 1983). Since the early 1970 s different genetic strains of lake trout have been stocked in Lake Ontario by US and Canadian agencies in an effort to reestablish self-sustaining populations (Elrod et al., 1996). Recently, seasonal habitat use was quantified (Ivanova et al., Unpublished data) implying two general contingents exist in Lake Ontario - more typical individuals remaining in deeper regions through the stratified summer season and spending the fall and winter in shallower regions, and atypical individuals that spent considerable time in shallower regions year-round. Yet, the movement behavior of lake trout and any underlying patterns are poorly understood. These unknowns are problematic given the species is a focus of binational rehabilitation efforts (Lantry et al., 2014).

Given their life-history and circumpolar distribution, lake trout are a model species to study iteroparous, potamodromous species' spatio-temporal movement ecology and migratory patterns in large lakes. The gained knowledge contributes life-history details associated with movement that are relevant for rehabilitation and understanding of lake trout, and other large predator freshwater fish species, population dynamics and role in ecosystem function. As such, this study is relevant to managers, decision-makers, and conservation and theoretical ecologists alike. The objectives of this study were to: 1) understand the movements of lake trout between regions and seasons and determine whether these could be classified as migrations; 2) determine the timing and year-to-year consistency of movements/migrations; and 3) quantify movement/migration route(s) relative to bathymetry. We predicted that: 1) consistent with definitions of migratory behavior, annual, inter-individual and route selection synchrony would be characteristic during fall pre-spawning movements, and 2) synchrony in route selection by individuals between years but asynchrony among individuals would be characteristic 
of the return movements. We used passive acoustic telemetry to track the movements of lake trout in Lake Ontario for a period of $\sim 2.5$ years to address these objectives.

\section{Methods}

\section{Study site}

Lake Ontario is the 13th largest lake by volume globally and has maximum depth of $245 \mathrm{~m}$. The eastern basin includes $1,657 \mathrm{~km}^{2}$ of islands and offshore areas with depths up to $40 \mathrm{~m}$ (Fig. 1 Right inset). The eastern basin is separated from the lake's deep main basin by the Duck Galloo Ridge, which is bisected by the Simcoe Island, St. Lawrence and Duck Galloo channels. Lake trout are known to use the eastern basin for spawning in the fall (Fitzsimons, 1995b). In this study, 'eastern Lake Ontario' would refer to the eastern quarter of the main basin in addition to the eastern basin and Duck-Galloo Ridge (as per extent shown in Fig. 1 right inset). 'Main basin' would be used to identify the deeper areas (> $50 \mathrm{~m}$ ) in eastern Lake Ontario. Lake bathymetry (i.e. depth range available for occupancy in the eastern basin [0 to $40 \mathrm{~m}$ ] versus the main basin [0 to $>60 \mathrm{~m}]$ ) is used as defining feature when referring to habitat or habitat switch.

\section{Acoustic telemetry}

We used fixed-station acoustic telemetry $(n=196$ permanent receivers in the eastern basin and $n=82$ in the western basin Lake Ontario; 69-kHz VR2W, Innovasea, Bedford, Nova Scotia, Canada; Fig. 1) to track lake trout movements across $\sim 2.5$ years. Receivers were spaced $\sim 2 \mathrm{~km}$ apart in the St. Lawrence channel. Receivers outside the channel and at the Duck-Galloo Ridge were spaced $\sim 2.5 \mathrm{~km}$ apart, in the eastern basin 5-10 km apart, and at the west end of the lake 5-10 km apart. Receivers were anchored in place via concrete blocks ( $62 \mathrm{~kg}$ ), positioned upward, floated at $2 \mathrm{~m}$ off the substrate via two $28 \mathrm{~cm}\left(11^{\prime \prime}\right)$ trawl floats, all connected by $11 \mathrm{~mm}$ (7/16") polypropylene rope. We tagged nine lake trout at Main Duck Island (43.927653, -76.618055; Fig. 1) on October 26, 2016, 21 lake trout at Charity shoal $(44.042179,-76.483863)$ on November 3, 2016, and another 20 at Charity shoal on November 8, 2017. Both years, fish were caught via multifilament gill nets set for 20-24 h (30 m each of 64, 76 and $89 \mathrm{~mm}$ stretch monofilament mesh), and held prior to surgery in 600-L tanks in which aerated lake water was continuously delivered; fish were held $<2$ hrs. A separate water tank (50 L) was filled with a mixture of lake water and anesthetic ( $4 \mathrm{~g} \mathrm{MS}-222$ and $8 \mathrm{~g} \mathrm{NaHCO}_{3}$ buffer per 10L of water) and used to prepare the fish for the procedure. Surgeries were performed according to the protocol described in Ivanova et al. (Unpublished data); total length was measured, and fin-clip markings and sex (if known) recorded. All fish (mean total length $771 \mathrm{~mm} \pm 57.9 \mathrm{SD}$ ) were tagged with V16 acoustic transmitters (hereafter tags; $68 \mathrm{~mm}$ length x 16 mm diameter; $10.3 \mathrm{~g}$ weight in water; nominal delay $180 \mathrm{~s}$; estimated battery life $3650 \mathrm{~d}$; Innovasea, Bedford, NS, Canada).

\section{Data analysis}

Lake trout were tracked from December 1, 2016 to April 30, 2019 in Lake Ontario. R statistical software (version 3.6.1) and ArcMap (version 10.3.1) were used for analysis and graphing, respectively. False 
detection filtering was performed on all available detections using the White-Mihoff Filtering Tool (White et al., 2014) with range of $1,600 \mathrm{~m}$ based on $80 \%$ detection efficiency (Klinard et al., 2019). Nine individuals were removed from analysis due to lack of sufficient data to provide meaningful contributions. Three other individuals (IDs 16853, 16859 and 16876) either expelled the tag or experienced mortality (determined from detections pattern) and partial data were used up to $24 \mathrm{~h}$ prior to detection pattern change. Cut off time was chosen after comparison of their movements to other fish to ensure included data were consistent with overall behaviors. Partial data inclusion is not likely to bias our results as all calculations were performed separately for each individual and then means taken where necessary (see below). A total of 2,820,990 detections were used for further analysis based on 41 individuals.

For statistical analysis and examination of individual movements we used centers of activity (Simpfendorfer et al., 2002). A random location near a receiver was assigned to each detection based on probability from curves generated by range tests for V16 tags in the study area (Klinard et al., 2019). Using position averaging of all of these locations occurring during a $30 \mathrm{~min}$ interval, centers of activity (CoA) were then calculated for each individual. To identify timing of switch between the eastern and main basins, and examine for patterns, we calculated daily means for each individual's latitude and longitude and plotted against time. We fit a linear regression function to various periods for latitude (Fig. 2) until best fit was identified with breakpoints selected based on regression results with lowest residual error. The identified fall periods were used for further analysis.

To quantify the main to eastern basin (also referred to as 'fall') movement corridors, we used network analysis with all associated detections (not CoAs). For this analysis, receivers were assigned to a group based on bathymetry. Eastern Lake Ontario receivers were grouped as seen in Fig. 3a, whereas all western basin receivers were excluded from this analysis (also shown in Fig. 3a for reference) because our fish were not detected on these receivers during the timespan of interest. We used igraph package in $\mathrm{R}$ (Csardi \& Nepusz, 2006) to create and analyze the networks. Due to the prolonged period for eastern to main basin movements, we did not use network analysis to infer corridors, as it would have included movements of exploratory nature. Instead, we used individual-level analysis.

Individual-level analysis was used to confirm habitat switch breakpoints and numbers of individuals using each corridor. For this purpose, movement trajectories were generated from the CoAs using adeHabitatLT package in R (Calenge, 2006), and each trajectory was examined, and date and corridor used recorded. We defined migration date as the date when an individual moved from one region to another and remained there $>7$ days. For individuals with two or more years of data we compared interannual consistency of dates and corridors of movements.

\section{Results}

Based on latitude-date regressions, lake trout movements from the main to eastern basin in 2017 occurred between Oct. 10 to Nov. 18, and in 2018 between Oct. 10 and Nov. 13 (Fig. 2a). All individuals 
made the transition in a single day. Inter-annual comparison of lake trout fall movements was possible for 18 individuals with data for 2 years (Table 1). There were six lake trout with inter-annual movements that occurred with $<4$ days difference between years and five of these showed consistencies in the migration route. Most inter-annual movements were consistent by route and use of the St. Lawrence channel ( $n=14$ for both).

Table 1

Fall (main to eastern basin) movements of lake trout in eastern Lake Ontario per month and year, interannually and based on consistency per month and route use. Note: all are expressed as percentage of

total grouped by year or for inter-annual comparison separated by double lines. StL = St. Lawrence channel, SI = Simcoe Island channel, BR = Black River channel, S'S = both St. Lawrence and Simcoe Island channels, BR'SI = both Black River and Simcoe Island channels.

\section{Movements per month and year}

\begin{tabular}{|lll|}
\hline & 2017 (\%) & 2018 (\%) \\
\hline September & 0 & 1 \\
\hline October & 75 & 88 \\
\hline November & 25 & 12 \\
\hline Inter-annual movements in same month or < 10 days apart if different month & $\%$ IDs \\
\hline Earlier (<10 days) & 47 \\
\hline Earlier (> 10 days) & 11 \\
\hline Later (<10 days) & 26 \\
\hline Inter-annual movements occurring in different months & $\%$ IDs \\
\hline Earlier (> 10 days) & 11 \\
\hline Later (>10 days) & 5 \\
\hline Inter-annual movements consistent by route & $\%$ IDs \\
\hline StL & 67 \\
\hline SI & 07 \\
\hline BR & 0 \\
\hline Inter-annual movements non-consistent by route & 14 \\
\hline S'S & $\%$ IDs \\
\hline BR'SI & 14 \\
\hline
\end{tabular}

During the winter, one lake trout moved between the eastern and western basins based on longitudinal daily-averaged CoA positions, and three others to the north-western part of the main basin (Fig. 2b). For the remainder of the year, lake trout displayed no major movement trends, although during June/early 
July and December there was evidence of the population being more concentrated along the longitudinal gradient versus widely distributed, respectively. Winter periods had overall low proportions of unique lake trout detected per day (Fig. 2c) and may account for the wider latitudinal spread of observations in these months.

Latitude-date regressions showed that eastern to main basin movements in 2017 occurred between May 12 and Sep 08, and in 2018 between Apr 09 and Sep 09 (Fig. 2a). Individual-level examination was possible for 37 lake trout and of these 18 had two years of data for inter-annual comparison and five had three years of data (Table 2). There were three loosely defined periods over which movement occurred: 1 ) in Dec-Jan, i.e. after spawning in Nov; 2) in Apr-May; and 3) sporadically later in the summer (Jun-Aug). Most eastern to main basin movements were consistent by date and route and used both St. Lawrence and Simcoe Island channel. For fish with known gender (15 males and 6 females tagged in 2016), female movements toward the main basin started in April each year, whereas males moved throughout all three periods. 
Table 2

Eastern to main basin movements of lake trout in eastern Lake Ontario per month and year, inter-annually and based on consistency per month and route use. Note: all are expressed as percentage of total grouped by year or for inter-annual comparison separated by double line. StL = St. Lawrence channel, SI = Simcoe Island channel, BR = Black River channel, S'S = both St. Lawrence and Simcoe Island channels,

BR'SI = both Black River and Simcoe Island channels.

\begin{tabular}{|llllll}
\hline \multicolumn{2}{l}{ Movements per month and year } & & & \\
\hline 2016-17 & \% IDs: & 2017-18 & \% IDs: & 2018-19 & $\begin{array}{c}\% \\
\text { IDs: }\end{array}$ \\
\hline 2016-Dec & 15 & 2017-Dec & 21 & 2018-Nov & 2018-Dec \\
\hline 2017-Jan & 8 & 2018-Jan & 9 & 2019-Apr & \\
\hline 2017-Apr & 23 & $\begin{array}{l}\text { 2018- } \\
\text { Mar }\end{array}$ & 9 & & \\
\hline 2017-May & 31 & 2018-Apr & 19 & & \\
\hline 2017-Jun & 15 & 2018- & 21 & & \\
\hline 2017-Aug & 8 & 2018-Jun & 9 & & \\
\hline & & 2018-Jul & 9 & & \\
\hline
\end{tabular}

Inter-annual movements in same month or $<10$ days apart if different month

$\%$ IDs

Earlier

53

Later

6

Inter-annual movements in different month

$\%$ IDs

Earlier

18

Later

23

Inter-annual

$\%$ IDs

Inter-annual movements non-consistent by route

movements consistent by

route

StL

42

S'S

29

SI

29

BR

0 
Network analysis revealed that the St. Lawrence Channel was the most utilized corridor for all years (Fig. 3a and b). Simcoe Island and Black River channels had similar usage, but much less so than St. Lawrence. A total of 21 and 34 lake trout individuals were used for individual-level analysis on the main to eastern basin movements of lake trout for 2017 and 2018, respectively (Table 1). During main to eastern basin migration in 2017, more lake trout $(n=17)$ used the St. Lawrence channel compared to the Simcoe Island $(n=2)$ and Black River $(n=2)$ channels, $(n=3$ were unknown due to a lack of data for this period). In 2018, 23 lake trout used the St. Lawrence channel, five the Simcoe Island channel, and six the Black River channel ( $n=7$ could not be determined due a lack of data). Many individuals travelled to the eastern basin prior to these dates, but duration was never longer than 2-3 days and always returned to the convergence location, therefore the movements seemed to be of exploratory nature.

Regardless of eastern to main basin migration date, all lake trout converged yearly south of Duck-Galloo Ridge in the main basin (Fig. 3a) prior to the main to eastern basin migration.

\section{Discussion}

Lake trout movements in Lake Ontario prior to spawning showed inter-annual repeatability and synchrony between individuals, and thus were classified as pre-spawning migrations. The migration occurred over the span of one-month period starting in mid-October each year and involved movements to shallower water in the eastern basin of the lake. Movements following spawning from the eastern to the main basin were asynchronous between individuals, characterized by multiple patterns between areas over three periods of time, thus suggestive of a dispersal strategy. However, inter-annual consistency in the timing of eastern to main basin movements across individuals suggests the coexistence of contingents with potentially facultative versus obligatory migratory strategies. Evidence for convergence between contingents was observed in the fall prior to spawning migration in both years. Inter-annual synchrony was typical for all individual migrations in both directions in terms of date but not for corridor selection. Generally, there was relatively low variability in the start date of the main to the eastern basin movements between years, but eastern to main basin movements occurred earlier in 2018. This study demonstrated migratory patterns and convergence of lake trout, thus, contributing novel and useful information for rehabilitation efforts and adding to the existing knowledge of potamodromous iteroparous top predators in large lakes.

Differentiation between general non-repeated movements and migratory patterns is an important step to understanding the movement ecology of species. Our results show that inter-annual convergence, repeatability and timing of occurrence of the movements, were all typical for the pre-spawning fall movements of lake trout in eastern Lake Ontario. Thus, these movements were classified as migrations. Observations of repeated, non-random movements (i.e. not classified as exploratory in nature) for lake trout are rare in the literature, although long-distance movements in the Great Lakes have been documented. For example, Rybicki (1990) and Ivanova et al. (Unpublished data), recorded lake trout cross-lake movements $>200 \mathrm{~km}$ in Lake Michigan and Ontario, respectively. Both of these studies described the movements as dispersal or exploratory behaviors, because observations were for a single 
year and few individuals. The movements we observed $(\sim 20-50 \mathrm{~km})$ were not as large, but repeatability between years, synchrony between individuals, and the occurrence during a period when the species are looking for particular conditions associated to spawning, are defining characteristics of many migrations.

Post-spawning migrations for some species are more difficult to distinguish from other movements due to the lack of synchrony among individuals due to divergent migration, a strategy used by lake sturgeon (Acipenser fulvescens) in the Huron-Erie Corridor (Kessel et al., 2018). Such migrations have been reported for lake trout, Riley et al. (2018) observed repeated long-distance post-spawning movements in Lake Huron, which were classified as migratory. In our study, the post-spawning behaviors were nonsynchronous with inter-individual variation in movements patterns. For example, some individuals moved to the main basin within two months post-spawning without further returns to the eastern basin until the next fall, whereas other fish undertook repeated trips of short duration ( $<3$ days) between these areas during the spring and summer. However, given individuals showed inter-annual consistency in their movements from the eastern to the main basin (for periods $>7$ days) suggests that divergent migratory strategy patterns and habitat use exist in lake trout in large lakes. This would subdivide the eastern Lake Ontario lake trout population into "contingents" (Gahagan et al., 2015; Secor, 1999).

Different migratory strategies include obligate and facultative migrants and some species show distinct variations within or among populations, including exhibiting divergent migration (Bowler \& Benton, 2005; Dingle, 2014). All of these have been documented for a number of taxa (Brodersen et al., 2014; Herman et al., 2005; Kessel et al., 2018). Based on our eastern to main basin migration periods, contingents belonging to the earliest movement period (December-January) could be obligate migrants because they moved even though environmental conditions didn't change, i.e. migrate regardless of the environmental conditions. Whereas individuals belonging to the latter two periods (i.e. April-May, and June-August), would appear to exhibit facultative strategy and likely migrate based on thermoregulatory constraints (Ivanova et al., Unpublished data) and/or in search of more profitable foraging opportunities. The cooccurrence of both of these strategies is plausible for lake trout, considering the species show large variation in the size of their home ranges and how far they disperse from a location (Riley et al., 2018; Schmalz et al., 2002; Ivanova et al., Unpublished data). Such co-occurrence is also common for other species, such as roach (Rutilus rutilus) populations in Lake Krankesjon, Sweden, which include fish with either of these strategies plus individuals that are obligatory residents (Brodersen et al., 2014).

Consistency in the migratory strategy is yet another aspect of migration (B. B. Chapman et al., 2012) with some fish being more flexible in whether they migrate year to year (Brodersen et al., 2014). In our study, all individuals migrated both years and thus exhibited consistency, providing evidence that the movements from the eastern to the main basin were migratory behavior as well but divergent in nature due to the coexistence of contingents.

Migratory strategies in animals are often based on genetically determined life-history types or behaviors (Gross, 1987). Given our results showed three periods of movement towards the main basin for lake trout in Lake Ontario, these differing migratory behaviors may be due to the existence of contingents related to various genetic strains stocked by management. For example, several stocked strains (e.g. Seneca and 
Klondike) are associated with deeper water preference and movement to and from shoals around the time of spawning (Gunn, 1995), while other strains (Superior and Huron-Parry Sound) are generally associated with shallower water preference throughout the year (Zimmerman \& Krueger, 2009). No genetic information was available for our fish and thus we were unable to examine for correlations between contingents and strain. However, the known preferences of the stocked genetic strains seem to be represented among the contingents observed in our study and based on our results for eastern to main basin movements, support the notion for the presence of at least two contingent migratory strategies.

Knowledge of the convergence location and understanding its connectivity to the two basins of interest is an essential step to assess how migratory behaviors are modified by the abiotic environment, and bathymetry in particular. Our results showed that the deepest route, i.e. the St. Lawrence Channel, was the most utilized corridor for lake trout movements in either direction. This route was more consistently used during migration towards the eastern basin, compared to migration towards the main basin. The St. Lawrence Channel is located between the Simcoe Island and Black River Channels, and is deeper ( $60 \mathrm{~m}$ versus $\sim 40 \mathrm{~m}$ ) and much wider. Given the occurrence of convergence and its location south of DuckGalloo Ridge (see Fig. 1), and these characteristics of the St. Lawrence Channel suggest that centrality and bathymetry are driving route selection of migratory large groups. This is supported by our results that during the non-synchronous movement from the eastern to the main basin almost an equal number of individuals used the Simcoe Island channel $(n=24)$ and the St. Lawrence channel $(n=21)$.

Understanding species migratory behaviors and strategies in large lakes is useful for management applications and to broader ecological theory. From management and restoration perspective, understanding migratory patterns and contingent co-existence can inform on the success and implications of employing various stocking strategies. For example, lake trout restoration plans were strategically oriented to stocking a diversity of genetic strains to improve survival given changing Lake Ontario environmental conditions and to broaden the occupied depth ranges (Lantry et al., 2014). Our results show that migrations and movements between environmental patches occur and support the notion that different habitats are being utilized throughout the seasons by different contingents providing feedback to management that strategies are successfully meeting objectives.

From a broader perspective, these results can be used to inform rehabilitation efforts for fish at any lake globally that offers a variety of habitats. From an ecological theory perspective, but also relevant to management, knowledge of migratory patterns versus general movements is an important step to understanding the general ecology of the species and their role and relative importance in and for the function of an ecosystem, and the demands on their bioenergetics. Our results document and provide key information on the migration patterns of contingents, aggregation points and routes, which are all useful considerations in modelling to understand and predict community dynamics, nutrient cycling and overall ecosystem function. For example, lake trout are considered a key link between the benthic and pelagic near- and offshore areas in the cycling of energy (Ives et al., 2019; Ryder \& Kerr, 1990). Thus, understanding their migratory patterns (i.e. timing and route) and drivers, and co-existence of contingents allows to map more accurately repeated and non-repeated temporal and even physical connections

Page $12 / 21$ 
between these areas and how nutrients are being transported. Given this, our results provide valuable insights and usefulness to both theoretical science and management.

\section{Conclusions}

Historically, the difficulty to track aquatic animals continuously through time has been the reason for the limited knowledge on potamodromous migrations of iteroparous species in large lakes. Without this foundation, a general, but inaccurate, assumption is made that all individuals of the same species exhibit a common movement and/or migratory behavior (Conrad et al., 2011). Using acoustic telemetry, this study addressed this gap. In particular, we identified at least two lake trout contingents and provided a continuous and improved understanding of how contingent behaviors related to temperature and habitat selection observed in previous studies correlate to migratory behavior. All lake trout, independent of contingency, synchronized their pre-spawning migrations and converged at a location other than their spawning grounds, and, consistent with divergent migrations, dispersed post-spawning in a nonsynchronized manner. Given the importance of lake trout in temperate lakes, the insights gained by our study are useful for informing current rehabilitation and more theoretically, add to the existing knowledge of movement and migration ecology of a potamodromous top predator species in a large lake.

\section{Declarations}

\section{Ethics approval and consent to participate}

The Ontario Ministry of Natural Resources and Forestry Animal Care Committee (AMS_ACC_140) in compliance with the Canadian Council on Animal Care guidelines approved animal methodology.

\section{Consent for publication}

Not applicable.

\section{Availability of Data and Material}

Data will be archived in the Zenodo repository with 12-month embargo due to it still undergoing analyses for other projects but can be made available upon reasonable request to the corresponding author.

\section{Competing interests}

The authors declare that they have no competing interests.

\section{Funding}

Financial support was received through the Canada-Ontario Agreement on Great Lakes Water Quality and Ecosystem Health to TBJ, Canada Research Chair funding to ATF, and scholarships to SVI from University of Windsor and NSERC. This work was funded by the Great Lakes Fishery Commission (Grant ID 
\#2013_BIN_44024) by way of Great Lakes Restoration Initiative appropriations (Grant ID \#GL-00E23010). This paper is contribution 83 of the Great Lakes Acoustic Telemetry Observation System (GLATOS).

\section{Authors' Contributions}

SVI, TBJ and ATF conceived and designed the study, planned, led and participated in the field work, and contributed to and edited the manuscript. SVI performed all analysis and wrote the manuscript.

\section{Acknowledgements}

The authors would like to thank NYSDEC (Captain Alan Fairbanks, Jana Lantry, Michael Connerton, Nick Massa, Gaylor Massia), OMNRF (Brent Metcalfe, Mary Hanley, Al Maclntosh, Jeff Buckley), and USGS (Stacey Furgal) for assistance in netting and tagging the fish, and the OMNRF, DFO and USFWS vessel crews for servicing and downloading the acoustic receivers. Thanks are also extended to members and staff of the Great Lakes Acoustic Telemetry Observation System (GLATOS).

\section{Literature Cited}

Adkison, M. D., \& Cunningham, C. J. (2015). The effects of salmon abundance and run timing on the performance of management by emergency order. Canadian Journal of Fisheries and Aquatic Sciences, 72(10), 1518-1526. https://doi.org/10.1139/cjfas-2015-0174

Arai, T. (2014). Evidence of local short-distance spawning migration of tropical freshwater eels, and implications for the evolution of freshwater eel migration. Ecology and Evolution, 4(19), 3812-3819. https://doi.org/10.1002/ece3.1245

Bemis, W. E., \& Kynard, B. (1997). Sturgeon rivers: An introduction to Acipenseriform biogeography and life history. Environmental Biology of Fishes. https://doi.org/10.1007/0-306-46854-9_8

Binder, T.R., Cooke, S. J., \& Hinch, S. G. (2011). The Biology of Fish Migration. In A. P. Farrell (Ed.), Encyclopedia of Fish Physiology: From Genome to Environment (volume 3, pp. 1921-1927). San Diego: Academic Press. https://doi.org/10.1016/B978-0-1237-4553-8.00085-X

Binder, Thomas R, Marsden, J. E., Riley, S. C., Johnson, J. E., Johnson, N. S., He, J., Ebener, M., Holbrook, C. M., Bergstedt, R. A., Bronte, C. R., Hayden, T. A., \& Krueger, C. C. (2017). Movement patterns and spatial segregation of two populations of lake trout Salvelinus namaycush in Lake Huron. 43, 108-118. https://doi.org/10.1016/j.jglr.2017.03.023

Bowler, D. E., \& Benton, T. G. (2005). Causes and consequences of animal dispersal strategies: Relating individual behaviour to spatial dynamics. Biological Reviews of the Cambridge Philosophical Society, 80, 205-225. https://doi.org/10.1017/S1464793104006645

Brodersen, J., Chapman, B. B., Nilsson, P. A., Skov, C., Hansson, L. A., \& Brönmark, C. (2014). Fixed and flexible: Coexistence of obligate and facultative migratory strategies in a freshwater fish. PLOS ONE, 9(3), 
Calenge, C. (2006). The package adehabitat for the R software: a tool for the analysis of space and habitat use by animals. Ecological Modeling, 197, 516-519.

Chapman, B. B., Hulthén, K., Brodersen, J., Nilsson, P. A., Skov, C., Hansson, L. A., \& Brönmark, C. (2012). Partial migration in fishes: Causes and consequences. Journal of Fish Biology, 81(2), 456-478. https://doi.org/10.1111/j.1095-8649.2012.03342.x

Chapman, Ben B., Hulthén, K., Wellenreuther, M., Hansson, L.-A., Nilsson, J.-Å., \& Brönmark, C. (2014). Patterns of animal migrations. In L.-A. Hansson \& S. Åkesson (Eds.), Animal Movement Across Scales (pp. 11-35). Oxford University Press.

Christie, W. J. (1972). Lake Ontario: effects of exploitation, introductions, and eutrophication on the salmonid community. Journal Fisheries Research Board of Canada, 29, 913-929.

Conrad, J. L., Weinersmith, K. L., Brodin, T., Saltz, J. B., \& Sih, A. (2011). Behavioural syndromes in fishes: a review with implications for ecology and fisheries management. Journal of Fish Biology, 78(2), 395435. https://doi.org/10.1111/j.1095-8649.2010.02874.x

Csardi, G., \& Nepusz, T. (2006). The igraph software package for complex network research. InterJournal, Complex Sy, 1695. http://igraph.org.

Dingle, H. (2014). A taxonomy of movement. In Migration: The Biology of Life on the Move (Second Edi, pp. 3-12). Oxford University Press. https://doi.org/10.1093/acprof:oso/9780199640386.001.0001

Domeier, M. L., \& Nasby-Lucas, N. (2013). Two-year migration of adult female white sharks (Carcharodon carcharias) reveals widely separated nursery areas and conservation concerns. Animal Biotelemetry, 1(1). https://doi.org/10.1186/2050-3385-1-2

Elrod, J. H., Gorman, R. O., Schneider, C. P., \& Schaner, T. (1996). Geographical Distributions of Lake Trout Strains Stocked in Lake Ontario. 22(4), 871-883. https://doi.org/10.1016/S0380-1330(96)71008-0

Fitzsimons, J. D. (1995a). Assessment of Lake Trout Spawning Habitat and Egg Deposition and Survival in Lake Ontario. Journal of Great Lakes Research, 21(Suppl. 1), 337-347. https://doi.org/10.1016/S03801330(95)71108-X

Fitzsimons, J. D. (1995b). Assessment of Lake Trout Spawning Habitat and Egg Deposition and Survival in Lake Ontario. Journal of Great Lakes Research, 21(Suppl 1), 337-347. https://doi.org/10.1016/S03801330(95)71108-X

Fitzsimons, J. D., Brown, S. B., Honeyfield, D. C., \& Hnath, J. G. (1999). A review of early mortality syndrome (EMS) in Great Lakes salmonids: relationship with thiamine deficiency. Ambio, 28(1), 9-15. 
Gahagan, B. I., Fox, D. A., \& Secor, D. H. (2015). Partial migration of striped bass: Revisiting the contingent hypothesis. Marine Ecology Progress Series, 525, 185-197. https://doi.org/10.3354/meps11152

Gross, M. R. (1987). Evolution of diadromy in fishes. In American Fisheries Society Symposium I (pp. 1425). https://doi.org/evolution migration strategie tactique histoire de vie

Gunn, J. M. (1995). Spawning Behavior of Lake Trout: Effects on Colonization Ability. Journal of Great Lakes Research, 21(Supplement 1), 323-329. https://doi.org/10.1016/S0380-1330(95)71106-6

Hansen, Martin J., \& Stauffer, T. M. (1971). Comparative Recovery to the Creel, Movement and Growth of Rainbow Trout Stocked in the Great Lakes. Transactions of the American Fisheries Society, 100, 336-349. https://doi.org/10.1577/1548-8659(1971)100<336:crttcm>2.0.co;2

Hansen, Micheal J. (1999). Lake Trout in the Great Lakes: Basinwide stock collapse and binational restoration. In W. W. Taylor \& C. P. Ferreri (Eds.), Great Lakes fisheries policy and Management: a binational perspective (pp. 417-454). Michigan State University Press.

Harris, L. N., Moore, J. S., McDermid, C. G., \& Swanson, H. K. (2014). Long-distance anadromous migration in a fresh water specialist: The Lake Trout (Salvelinus namaycush). Canadian Field-Naturalist, 128(3), 260-264. https://doi.org/10.22621/cfn.v128i3.1604

Haynes, J. M., \& Keleher, C. J. (1986). Movements of pacific salmon in lake ontario in spring and summer: Evidence for wide dispersal. Journal of Freshwater Ecology, 3, 289-297.

https://doi.org/10.1080/02705060.1986.9665120

Herman, D. P., Burrows, D. G., Wade, P. R., Durban, J. W., Matkin, C. O., Leduc, R. G., Barrett-Lennard, L. G., \& Krahn, M. M. (2005). Feeding ecology of eastern North Pacific killer whales Orcinus orca from fatty acid, stable isotope, and organochlorine analyses of blubber biopsies. Marine Ecology Progress Series, 302, 275-291. https://doi.org/10.3354/meps302275

Ives, J. T., McMeans, B. C., McCann, K. S., Fisk, A. T., Johnson, T. B., Bunnell, D. B., Frank, K. T., \& Muir, A. M. (2019). Food-web structure and ecosystem function in the Laurentian Great Lakes-Toward a conceptual model. Freshwater Biology, 64(1), 1-23. https://doi.org/10.1111/fwb.13203

Kessel, S. T., Hondorp, D. W., Holbrook, C. M., Boase, J. C., Chiotti, J. A., Thomas, M. V., Wills, T. C., Roseman, E. F., Drouin, R., \& Krueger, C. C. (2018). Divergent migration within lake sturgeon (Acipenser fulvescens) populations: Multiple distinct patterns exist across an unrestricted migration corridor. Journal of Animal Ecology, 87(1), 259-273. https://doi.org/10.1111/1365-2656.12772

Klinard, N. V., Fisk, A. T., Kessel, S. T., Halfyard, E. A., \& Colborne, S. F. (2018). Habitat use and small-scale residence patterns of sympatric sunfish species in a large temperate river. Canadian Journal of Fisheries and Aquatic Sciences, 75, 1059-1069. https://doi.org/10.1139/cjfas-2017-0125 
Klinard, N. V, Halfyard, E. A., Matley, J. K., Fisk, A. T., \& Johnson, T. B. (2019). The influence of dynamic environmental interactions on detection efficiency of acoustic transmitters in a large, deep, freshwater lake. Animal Biotelemetry, 7(17). https://doi.org/10.1186/s40317-019-0179-1

Landsman, S. J., Nguyen, V. M., Gutowsky, L. F. G., Gobin, J., Cook, K. V., Binder, T. R., Lower, N., McLaughlin, R. L., \& Cooke, S. J. (2011). Fish movement and migration studies in the Laurentian Great Lakes: Research trends and knowledge gaps. Journal of Great Lakes Research, 37(2), 365-379. https://doi.org/10.1016/j.jglr.2011.03.003

Lantry, J., Schaner, T., \& Copeland, T. (2014). A Management Strategy for the Restoration of Lake Trout in Lake Ontario, 2014 Update. http://www.glfc.org/pubs/lake_committees/ontario/Lake Ontario_Lake_Trout_Strategy_Nov_2014.pdf

Muhlfeld, C. C., Giersch, J. J., \& Marotz, B. (2012). Seasonal movements of non-native lake trout in a connected lake and river system. Fisheries Management and Ecology, 19(3), 224-232.

https://doi.org/10.1111/j.1365-2400.2011.00821.x

Quinn, T. P. (2005). The Behavior and Ecology of Pacific Salmon and Trout. American Fisheries Society inAssociation with the University of British Columbia Press.

Righton, D., et al. (2016). Empirical observations of the spawning migration of European eels: The long and dangerous road to the Sargasso Sea. Science Advances, 2(10).

https://doi.org/10.1126/sciadv.1501694

Riley, S. C., Binder, T. R., Tucker, T. R., \& Krueger, C. C. (2018). Evidence of repeated long-distance movements by lake charr Salvelinus namaycush in Lake Huron. Environmental Biology of Fishes, 101(4), 531-545. https://doi.org/10.1007/s10641-018-0714-6

Robinson, T., \& Minton, C. (1989). The enigmatic banded stilt. Birds International L, 4, 72-85.

Russell, E. S. (1937). Fish Migrations. Biological Reviews, 12(3), 320-337.

https://doi.org/10.1111/j.1469-185X.1937.tb01199.x

Rybicki, R. W. (1990). Growth, survival, and straying of three lake trout strains stocked in the refuge of northern Lake Michigan.

Ryder, R. A., \& Kerr, S. R. (1990). Harmonic communities in aquatic ecosystems: a management perspective. In L. T. Van Densen, B. Teinmetz, \& R. H. Hughes (Eds.), In Management of Freshwater Fisheries. Proceedings of the EIFAC Symposium, Göteborg, Sweden, May 31 - June 3, 1988. (pp. 594623).

Schmalz, P. J., Hansen, M. J., Holey, M. E., McKee, P. C., \& Toneys, M. L. (2002). Lake Trout Movements in Northwestern Lake Michigan. North American Journal of Fisheries Management, 22(3), 737-749.

https://doi.org/10.1577/1548-8675(2002)022<0737:LTMINL>2.0.CO;2 
Schneider, C. P., Kolenosky, D. P., \& Goldthwaite, D. B. (1983). A joint plan for the rehabilitation of lake trout in Lake Ontario. GLFC, Ann Arbor, MI.

Secor, D. H. (1999). Specifying divergent migrations in the concept of stock: The contingent hypothesis. Fisheries Research, 43(1-3), 13-34. https://doi.org/10.1016/S0165-7836(99)00064-8

Simpfendorfer, C. A., Heupel, M. R., \& Hueter, R. E. (2002). Estimation of short-term centers of activity from an array of omnidirectional hydrophones and its use in studying animal movements. 32, 23-32. https://doi.org/10.1139/F01-191

Stewart, D. J., Weininger, D., Rottiers, D. V., \& Edsall, T. A. (1983). An Energetics Model for Lake Trout, Salvelinus namaycush: Application to the Lake Michigan Population. Canadian Journal of Fisheries and Aquatic Sciences, 40(6), 681-698. https://doi.org/10.1139/f83-091

Thurow, R. F. (2016). Life Histories of Potamodromous fishes. In P. Morais \& F. Daverat (Eds.), An Introduction to Fish Migration (pp. 29-54). CRC Press.

Vannini, C., Ferrantini, F., Ristori, A., Verni, F., \& Petroni, G. (2012). Betaproteobacterial symbionts of the ciliate Euplotes: origin and tangled evolutionary path of an obligate microbial association. ENVIRONMENTAL MICROBIOLOGY, 14(9, SI), 2553-2563. https://doi.org/10.1111/j.14622920.2012.02760.x

White, E., Mihoff, M., Jones, B., Bajona, L., \& Halfyard, E. (2014). White-Mihoff False Filtering Tool.

Wuebbles, D., Cardinale, B., Cherkauer, K., Davidson-Arnott, R., Hellmann, J., Infante, D., Johnson, L., de Loë, R., Lofgren, B., Packman, A., Seglenieks, F., Sharma, C. A., Sohngen, B., Tiboris, M., Vimont, D., Wilson, R., Kunkel, K., \& Ballinger, A. (2019). An Assessment of the Impacts of Climate Change on the Great Lakes. 74. http://elpc.org/wp-content/uploads/2019/03/Great-Lakes-Climate-Change-Report.pdf

Zimmerman, M. S., \& Krueger, C. C. (2009). An Ecosystem Perspective on Re-establishing Native Deepwater Fishes in the Laurentian Great Lakes. North American Journal of Fisheries Management, 29(5), 1352-1371. https://doi.org/10.1577/m08-194.1

\section{Figures}



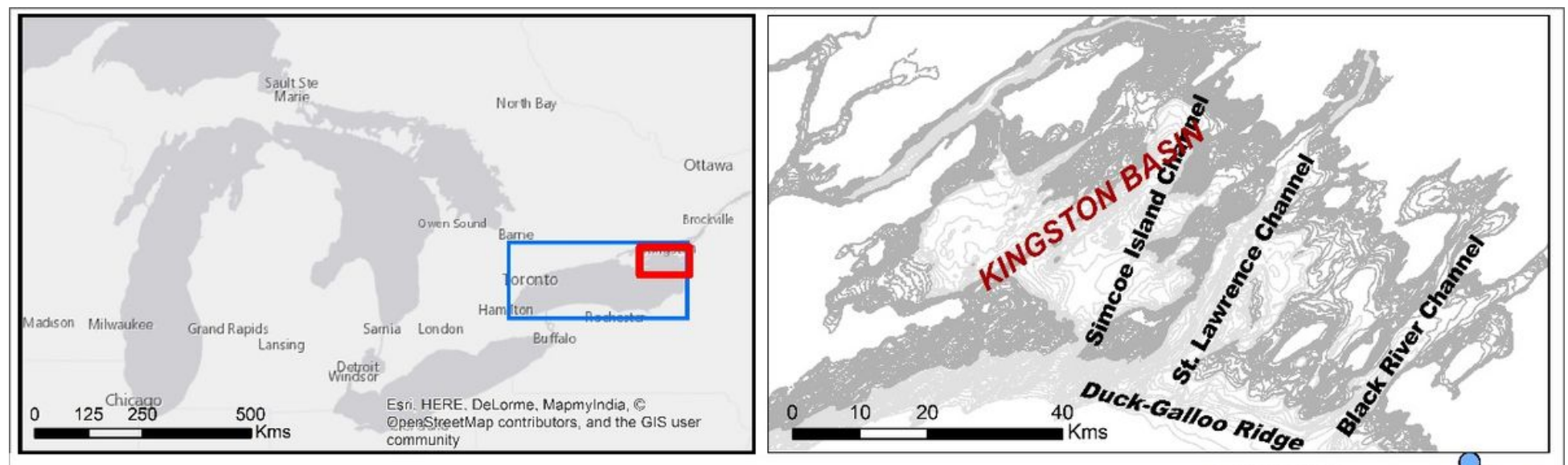

Permanent receivers 2016 - 2019

Receivers added in 2017

Receivers added in 2018

$\mathbf{X}$ Tagging locations

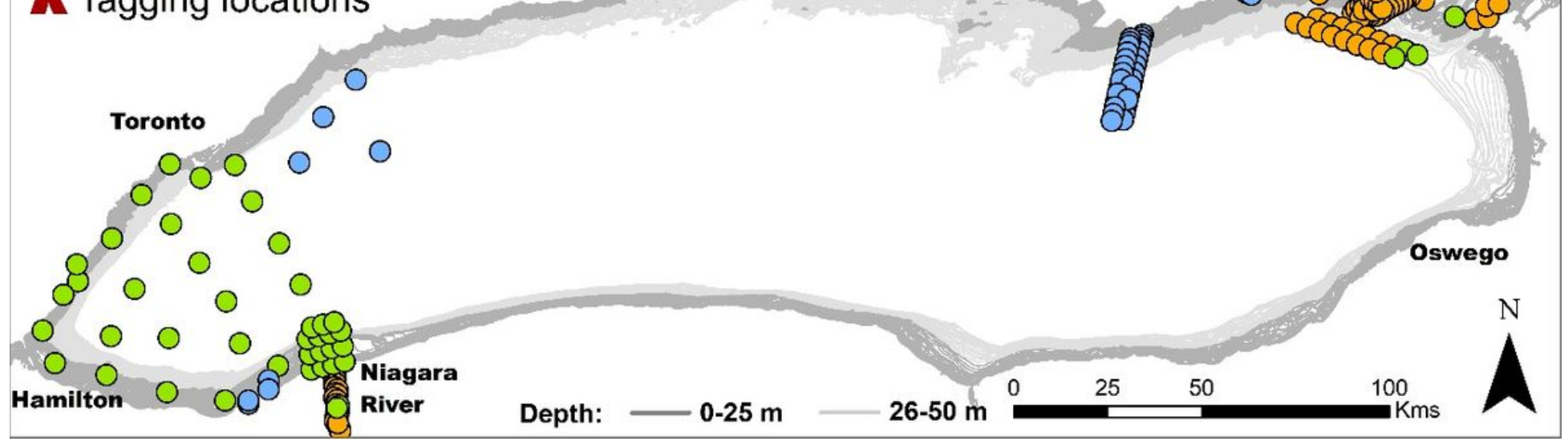

\section{Figure 1}

Map of receivers deployed by year in Lake Ontario used to infer timing of movement between basins and migration routes of lake trout. Left inset shows the relative location of Lake Ontario. Right inset shows the bathymetry and main features of the eastern basin. 
a)

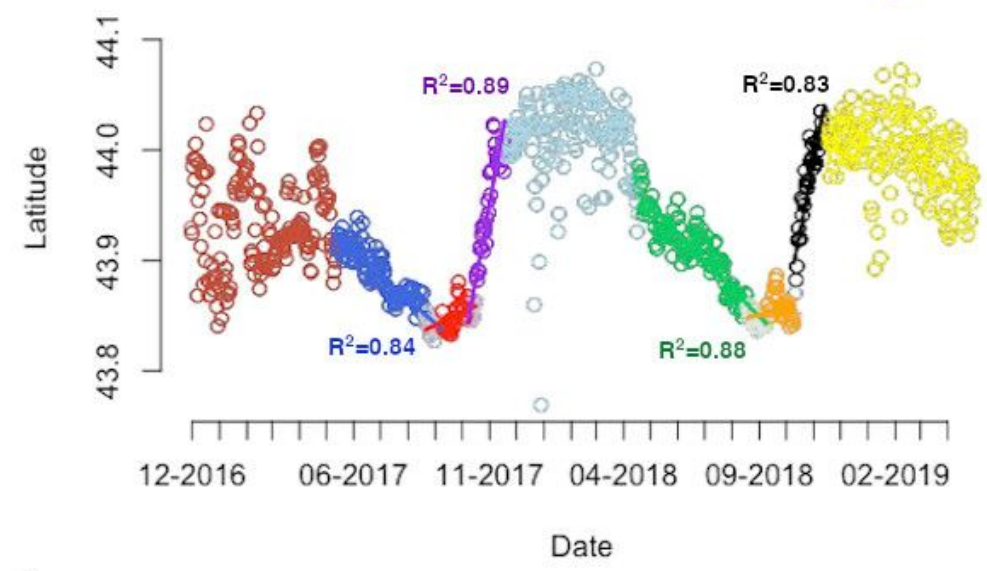

b)

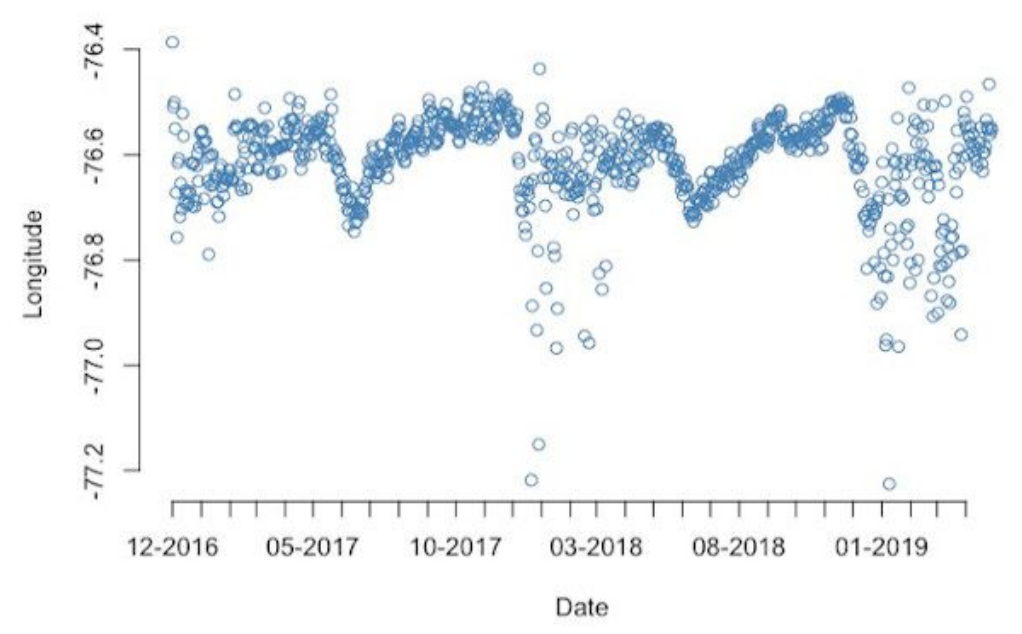

c)

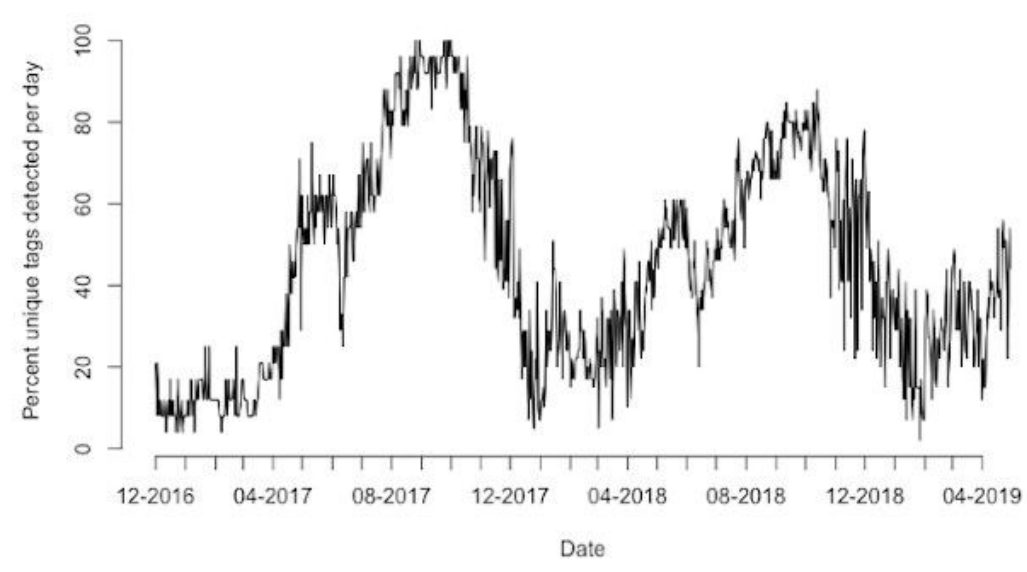

Figure 2

Timing of basin switch: a) eastern to main basin migration in 2017 occurred between May 12 and September 08, and in 2018 occurred between April 09 and September 09. Main to eastern basin migrations started October 10 in both years and were completed by November 10 and 13 in 2017 and 2018 , respectively; b) individual longitude mean daily locations versus date; and c) percent unique lake trout individuals detected per day over the study period. 
a)

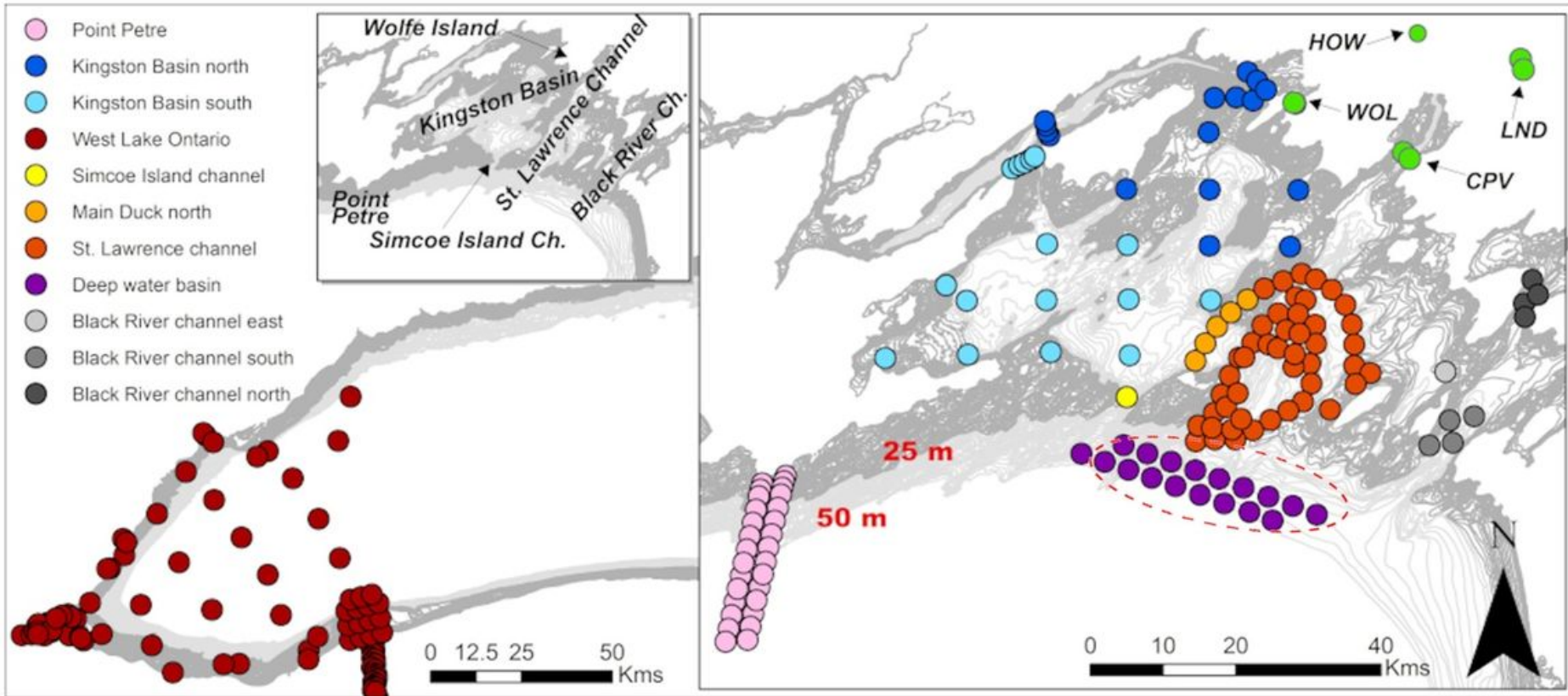

b)
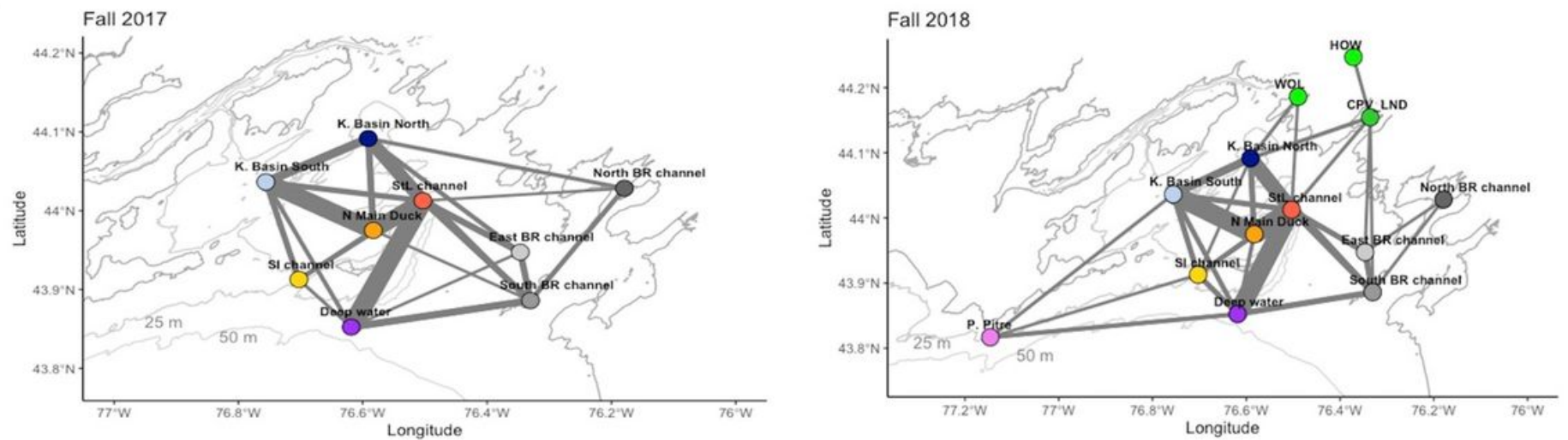

\section{Figure 3}

Movement corridors: a) Map showing the allocation of receivers based on location of interest with red dashed-line ellipse denoting the fall convergence location; b) fall 2017 and 2018 movement corridor usage. 